\title{
Comparative Effectiveness of Abatacept Versus Tumor Necrosis Factor Inhibitors in Patients with Rheumatoid Arthritis Who Are Anti-CCP Positive in the United States Corrona Registry
}

Leslie R. Harrold - Heather J. Litman - Sean E. Connolly •

Evo Alemao · Sheila Kelly · Sabrina Rebello • Winnie Hua •

Joel M. Kremer

Received: December 7, 2018 / Published online: March 13, 2019

(C) The Author(s) 2019

\section{ABSTRACT}

Introduction: Anti-citrullinated protein antibodies (ACPAs) are highly specific serological biomarkers that are indicative of a poor prognosis in patients with rheumatoid arthritis (RA). The effectiveness of biologic disease-modifying antirheumatic drugs (bDMARDs) with different mechanisms of action may vary, based on patients' serostatus. The aim of this study is to compare the effectiveness of abatacept versus tumor necrosis factor inhibitors (TNFis) in

Enhanced Digital Features To view enhanced digital features for this article go to: https://doi.org/10.6084/ m9.figshare.7764524.

Electronic supplementary material The online version of this article (https://doi.org/10.1007/s40744019-0149-3) contains supplementary material, which is available to authorized users.

\section{R. Harrold}

Departments of Medicine and Orthopedics, University of Massachusetts, Worcester, MA, USA

L. R. Harrold $(\bowtie) \cdot$ H. J. Litman · S. Rebello ·

W. Hua

Corrona, LLC, Waltham, MA, USA

e-mail: lharrold@corrona.org

S. E. Connolly · E. Alemao · S. Kelly

Bristol-Myers Squibb, Princeton, NJ, USA

J. M. Kremer

Albany Medical College and the Center for

Rheumatology, Albany, GA, USA patients with RA who were anti-cyclic citrullinated peptide antibody positive (anti-CCP+).

Methods: Abatacept or TNFi initiators with anti-CCP+ status $(\geq 20 \mathrm{U} / \mathrm{ml})$ at or prior to treatment initiation were identified from a large observational US cohort (1 December 2005-31 August 2016). Using propensity score matching $(1: 1)$, stratified by prior TNFi use $(0,1$ and $\geq 2)$, effectiveness at 6 months after initiation was evaluated. Primary outcome was mean change in Clinical Disease Activity Index (CDAI) score. Secondary outcomes included achievement of remission $(\mathrm{CDAI} \leq 2.8)$, low disease activity/remission $(\mathrm{CDAI} \leq 10)$, modified American College of Rheumatology 20/50/70 responses and mean change in modified Health Assessment Questionnaire score.

Results: After propensity score matching, the baseline characteristics between 330 pairs of abatacept and TNFi initiators (biologic naïve, $n=97$; TNFi experienced, $n=233$ ) were well balanced with absolute value standardized differences of $\leq 0.1$. Both overall, and in the biologic-naïve cohort, there were no significant differences in mean change in CDAI score at 6 months. However, in the TNFi-experienced cohort, there was a significantly greater improvement in CDAI score at 6 months with abatacept versus TNFi initiators $(p=0.033)$. Secondary outcomes showed similar trends.

Conclusions: Improvements in clinical disease activity were seen in anti-CCP + abatacept and 
TNFi initiators. TNFi-experienced anti-CCP+ patients with RA had more improvement in disease activity with abatacept versus TNFis, whereas outcomes were similar between treatments in the overall population and in biologicnaïve patients.

Trial Registration: ClinicalTrials.gov identifier: NCT01625650.

Funding: This study is sponsored by Corrona, LLC and funded by Bristol-Myers Squibb. Bristol-Myers Squibb funded the publication of this manuscript.

Keywords: Anti-TNF; DMARDs (biologic); Outcomes research; Rheumatoid arthritis

\section{INTRODUCTION}

Rheumatoid arthritis (RA) is characterized by the production of autoantibodies, including anti-citrullinated protein antibodies (ACPAs) and rheumatoid factor, which are estimated to be present in $50-80 \%$ of patients $[1,2]$. ACPAs, which are included in the 2010 American College of Rheumatology (ACR)/European League Against Rheumatism (EULAR) diagnostic criteria [3], can be present in serum before the onset of disease [4-6]. ACPAs are highly specific serological biomarkers that are indicative of a poor prognosis [7], including rapid disease progression, higher disease activity, more severe joint damage, and greater disability [8, 9]. ACPA positivity in patients with RA, compared with ACPA negativity, has been associated with worse clinical outcomes [7, 10], including higher rates of mortality [11].

There are some data that suggest biologic disease-modifying antirheumatic drugs (bDMARDs) with different mechanisms of action may be effective in various populations based on patient serostatus [12-14], and that bDMARD therapy itself may also impact seropositivity over time $[15,16]$. Therefore, ACPA status may be an important factor to consider as part of the treatment plan for patients with RA.

According to current EULAR treatment guidelines, the aim of RA treatment is to achieve sustained remission or low disease activity [7]. If there is no improvement in symptoms 3 months after the start of treatment, or treatment targets have not been reached within 6 months, therapy should be adjusted [7]. Conventional synthetic DMARDs (csDMARDs), such as methotrexate (MTX), should be considered as part of the first treatment strategy [7]. In patients who do not respond to treatment, the EULAR guidelines recommend either switching to or adding another csDMARD, or adding either a bDMARD or targeted synthetic DMARD (tsDMARD) [7]. Typically, the first choice of bDMARD used has been a tumor necrosis factor inhibitor (TNFi). Although these agents have proven effective, between 30 and $40 \%$ of patients develop an inadequate response, either due to a lack of primary response or the development of drug resistance or intolerance [17-21]. Current guidelines do not include any recommendations as to which bDMARD should be used after first-line treatment fails; instead, a treat-to-target approach is recommended by both EULAR and the ACR guidelines [7, 22].

Specific serological biomarkers that are indicative of a poor prognosis would be useful as part of a personalized treatment approach. One such biomarker, anti-cyclic citrullinated peptide antibody (anti-CCP, an ACPA surrogate), may be able to identify which patients will respond better to different treatments [23]. Previous data from the Corrona RA registry showed that anti-CCP status was associated with a better response to abatacept but not TNFis; however, this was not a head-to-head comparison and baseline characteristics, including age, disease duration, and treatment history, differed considerably between groups [13].

To the best of our knowledge, there are few comparative effectiveness studies evaluating responses to biologics in anti-CCP positive (anti-CCP+) patients. In this study, we used propensity score matching to compare the effectiveness of abatacept versus a TNFi (stratified by prior TNFi use: 0,1 or $\geq 2$ ) in a large cohort of anti-CCP+ patients with RA in the US. 


\section{METHODS}

\section{Data Source}

The Corrona RA registry is an independent, prospective, national, observational cohort. Patients are recruited from 175 private and academic practice sites across 41 states in the US, with 725 rheumatologists participating. As of March 2018, the Corrona database included information on 48,535 patients with RA. Data on 367,457 patient visits and 169,968 patientyears of follow-up observation time have been collected, with a mean patient follow-up of 4.3 (median 3.4) years.

To augment the number of patients with laboratory data available, we included patients who were included in the Corrona Comparative Effectiveness Registry to Study Therapies for Arthritis and Inflammatory Conditions (CERTAIN; ClinicalTrials.gov identifier: NCT01625650) study, which was a substudy of the Corrona RA registry that mandated regular data collection at 3-month intervals, with uniform collection of anti-CCP status for all patients initiating biologic treatment [24]. The Corrona CERTAIN substudy included a subset of patients with RA who were $\geq 18$ years of age, had initiated biologic therapy, had moderate or high disease activity [e.g., Clinical Disease Activity Index (CDAI) score $>10$ ] at enrolment, and were either biologic-naïve or TNFi-experienced. Patients were recruited from 43 sites in the US, with 117 rheumatologists participating. Enrolment was from November 2010 to May 2015 and included 1 year of follow-up with regular visits at 3-month intervals. A total of 2795 patients completed enrolment.

This study was carried out in accordance with the Declaration of Helsinki. All participating investigators were required to obtain full board approval for conducting noninterventional research involving human subjects with a limited dataset. Sponsor approval and continuing review was obtained through a central Institutional Review Board (IRB), the New England Independent Review Board (NEIRB; no. 120160610). For academic investigative sites that did not receive a waiver to use the central
IRB, full board approval was obtained from the respective governing IRBs and documentation of approval was submitted to Corrona, LLC prior to the initiation of any study procedures. All patients in the registry were required to provide written informed consent and authorization prior to participating.

\section{Study Population}

This analysis included patients with RA who initiated abatacept or a TNFi (adalimumab, certolizumab pegol, etanercept, golimumab, or infliximab) in the Corrona RA registry or the CERTAIN comparative effectiveness substudy between 1 December 2005 and 31 August 2016 (Fig. 1). Eligible patients were aged $\geq 18$ years, had a follow-up visit approximately 6 months after initiation of abatacept or TNFi treatment (visit window: 3-9 months using visit closest to 6 months if there were $>1$ visit), had CDAI score measured at or prior to initiation of treatment and within the appropriate timeframe prior to the visit (for initiations between visits, CDAI score measured within 4 months prior to initiation was used) and had anti-CCP+ status at or prior to initiation of treatment. Follow-up CDAI score was measured at the 6-month visit or at the time of switch if patients switched medications prior to the 6-month visit. In addition, patients were included if they had no prior exposure to other non-TNFi biologics or tsDMARDs and if they were not in remission $(\mathrm{CDAI} \leq 2.8)$ at the time of initiation. TNFi initiators with prior use of abatacept were excluded.

\section{Measures and Data Collection}

Data were collected during the study period from physician assessment and patient questionnaires completed during the clinical encounters. These forms were used to gather information on disease severity and activity [including serologic markers (anti-CCP) and components of ACR response criteria]; comorbidities; use of medications including steroids, csDMARDs, tsDMARDs and bDMARDs; and adverse events. As a strictly observational 


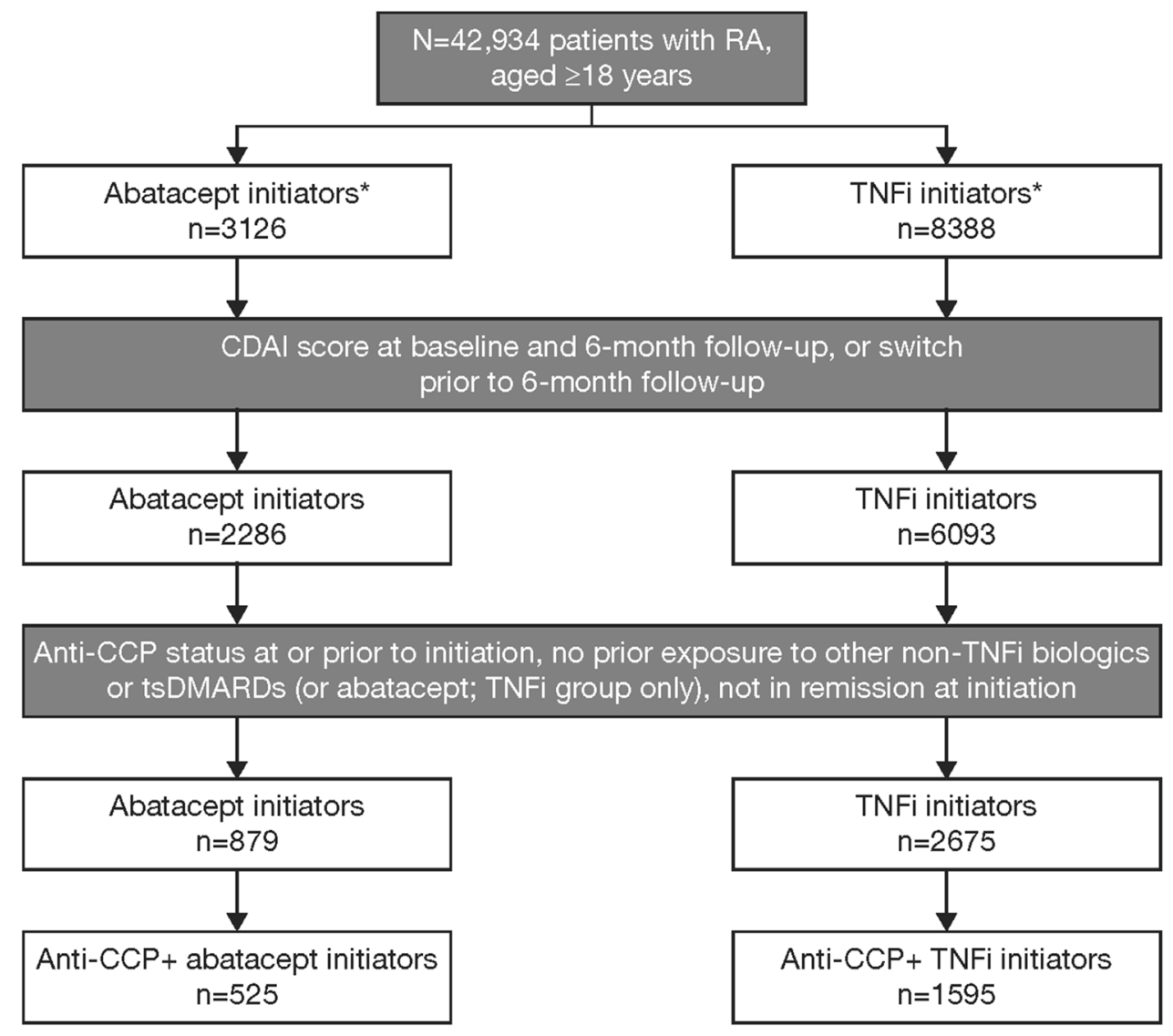

Fig. 1 Patient disposition. *Starting December 2005 or later. Anti-CCP anti-cyclic citrullinated peptide antibody, anti-CCP+ anti-CCP positive, CDAI Clinical Disease

registry that reflects typical clinical practice, the Corrona registry does not mandate that laboratory data, including serologic markers and acute-phase reactants, be collected. In the CERTAIN substudy, laboratory data were a requirement, with a centralized laboratory performing all assays. Data elements collected in both the overall Corrona RA registry and the CERTAIN substudy included CDAI (swollen joint count in 28 joints, tender joint count in 28 joints, Physician Global Assessment and Patient Global Assessment), modified ACR 20, 50, and $70 \%$ response (mACR20, mACR50, and mACR70) criteria (mACR is based on two out of four measures; it does not include erythrocyte sedimentation rate or C-reactive protein), the modified Health Assessment Questionnaire (mHAQ) assessing physical function and fivedimension EuroQol questionnaire (EQ-5D).
Activity Index, $R A$ rheumatoid arthritis, TNFi tumor necrosis factor inhibitor, tsDMARD targeted synthetic disease-modifying antirheumatic drug

Data on demographics, insurance status, comorbid conditions, RA disease characteristics, and RA medication were available for $>98 \%$ of patients.

\section{Drug Exposure Cohorts}

To balance for predisposing factors that may increase a patient's likelihood of receiving either abatacept or TNFis, a propensity scoreor the probability of treatment selection-was calculated for each eligible patient using baseline (at the time of drug initiation) patient demographics and disease characteristics [25]. Propensity score-matched treatment groups were created for abatacept and TNFis. Patients within each treatment group were matched 1:1 without replacement by prior TNF exposures of 
0,1 , and $\geq 2$ using the caliper method maximizing the number of patients including in the analysis. Separate propensity score models were fit, by prior biologic use stratum, to enable different covariates that were imbalanced within the stratum to be included (online supplementary table S1). Effectiveness at 6 months after treatment initiation was evaluated in both treatment groups.

\section{Study Outcomes}

The primary outcome was mean change in CDAI score over 6 months following initiation. Secondary outcomes at 6 months included achievement of remission $(\mathrm{CDAI} \leq 2.8)$, low disease activity or remission $(\mathrm{CDAI} \leq 10)$ in those with moderate or high disease activity at initiation, mACR20, mACR50, and mACR70 responses, and change from baseline in $\mathrm{mHAQ}$ score. Switching status among anti-CCP+ initiators of abatacept versus TNFis after propensity score matching was also assessed. Subgroup analyses were conducted by biologic-naïve and TNFi-experienced status at initiation.

\section{Statistical Analysis}

A formal statistical analysis plan was developed prior to conducting the study. Anti-CCP positivity was defined as anti-CCP $\geq 20 \mathrm{U} / \mathrm{ml}$. Baseline demographics and characteristics were compared between the treatment cohorts, and standardized differences were estimated. Standardized differences provide a measure of the imbalance in treatment groups with regards to the variable of interest, even if there are no statistically significant differences. The absolute value of the standardized difference of $\leq 0.1$ for the overall population [25] and $\leq 0.2$ within stratum (biologic naïve and TNFi experienced) was taken to indicate a negligible difference in the mean or prevalence of a covariate between treatment groups [25]. $p$ values were calculated using $t$ tests for normally distributed continuous variables and Chi-square tests for categorical variables. Propensity score models were fitted for each prior biologic category $(0,1$, and $\geq 2$ ) and patients were matched 1:1 within each stratum; the results of the matching using standardized differences are presented.

\section{RESULTS}

\section{Disposition and Clinical Characteristics of Anti-CCP+ Patients}

A total of 525 abatacept initiators and 1595 TNFi initiators met the inclusion criteria (Fig. 1). The baseline characteristics prior to propensity score matching (online supplementary table S2) showed that the two treatment groups differed (absolute value of the standardized differences $>0.1$ ) in terms of age, duration of RA, prior number of csDMARDs, prior biologic use, current MTX use, and current prednisone use. After propensity score matching, the overall population included 330 pairs of abatacept and TNFi initiators and, of these, 97 were biologic naïve and 233 were TNFi experienced (one prior TNFi, $n=164 ; \geq 2$ prior TNFis, $n=69)$.

After propensity score matching, the baseline characteristics between abatacept initiators and TNFi initiators were well balanced with absolute value standardized differences of $\leq 0.1$ in the overall population and of $\leq 0.2$ in the biologic-naïve and TNFi-experienced cohorts (Table 1). The exception to this was erosive disease in the overall population, which was present in a higher proportion of TNFi initiators than abatacept initiators. In the overall population, most patients were female and in their late 50s, with approximately a decade of disease duration. Approximately 30\% of patients had been enrolled in the CERTAIN substudy.

\section{Primary Efficacy Outcome}

In the overall population, there was no significant difference in mean change in CDAI score at 6 months between abatacept initiators and TNFi initiators (abatacept initiators, - 9.85 [95\% confidence interval $(95 \% \quad \mathrm{CI})-11.40$ to - 8.30]; TNFi initiators, -8.53 [95\% CI - 10.09 to -6.98$] ; p=0.24 ;$ Fig. 2 ). Similar results were shown for biologic-naïve patients (abatacept 


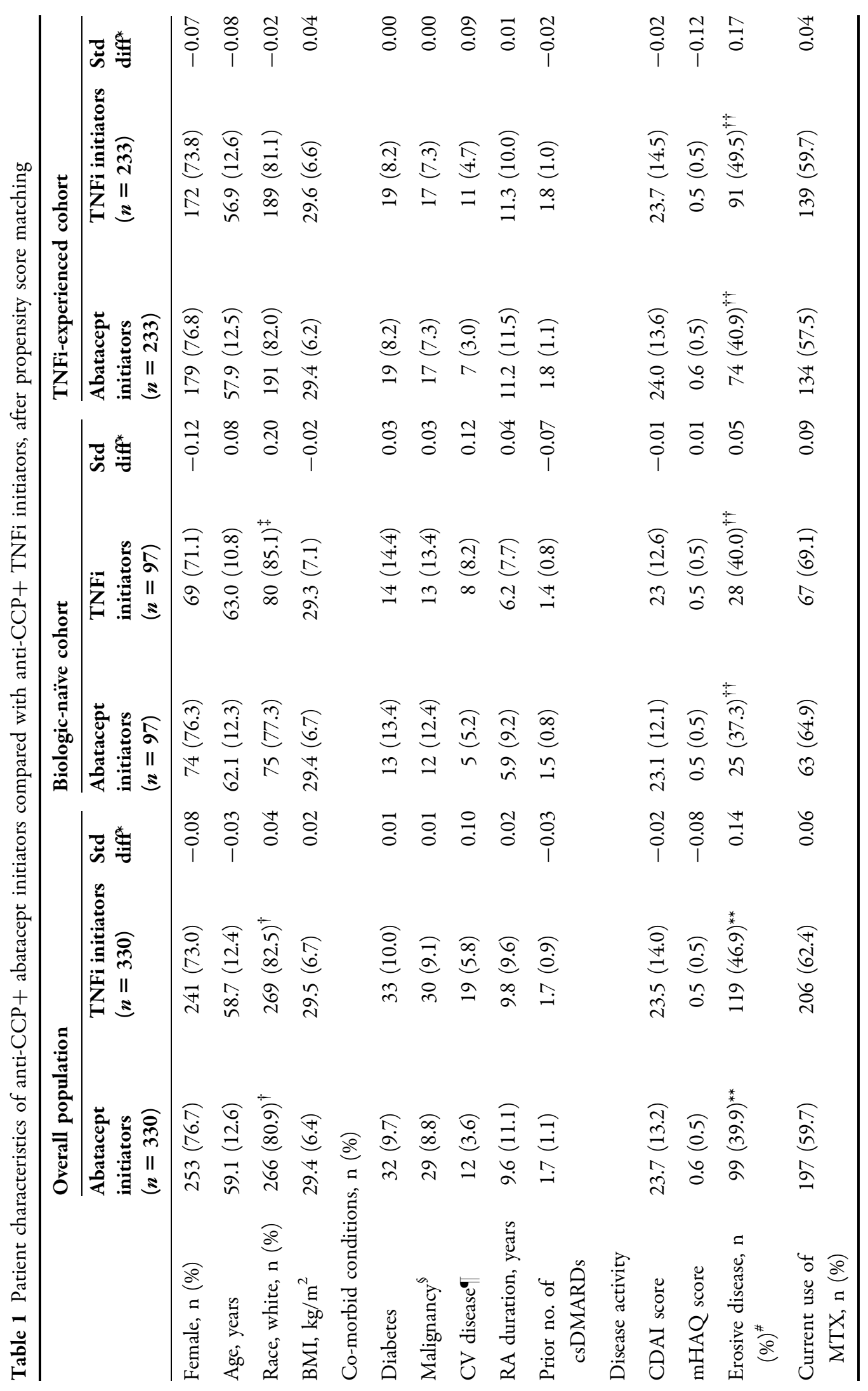




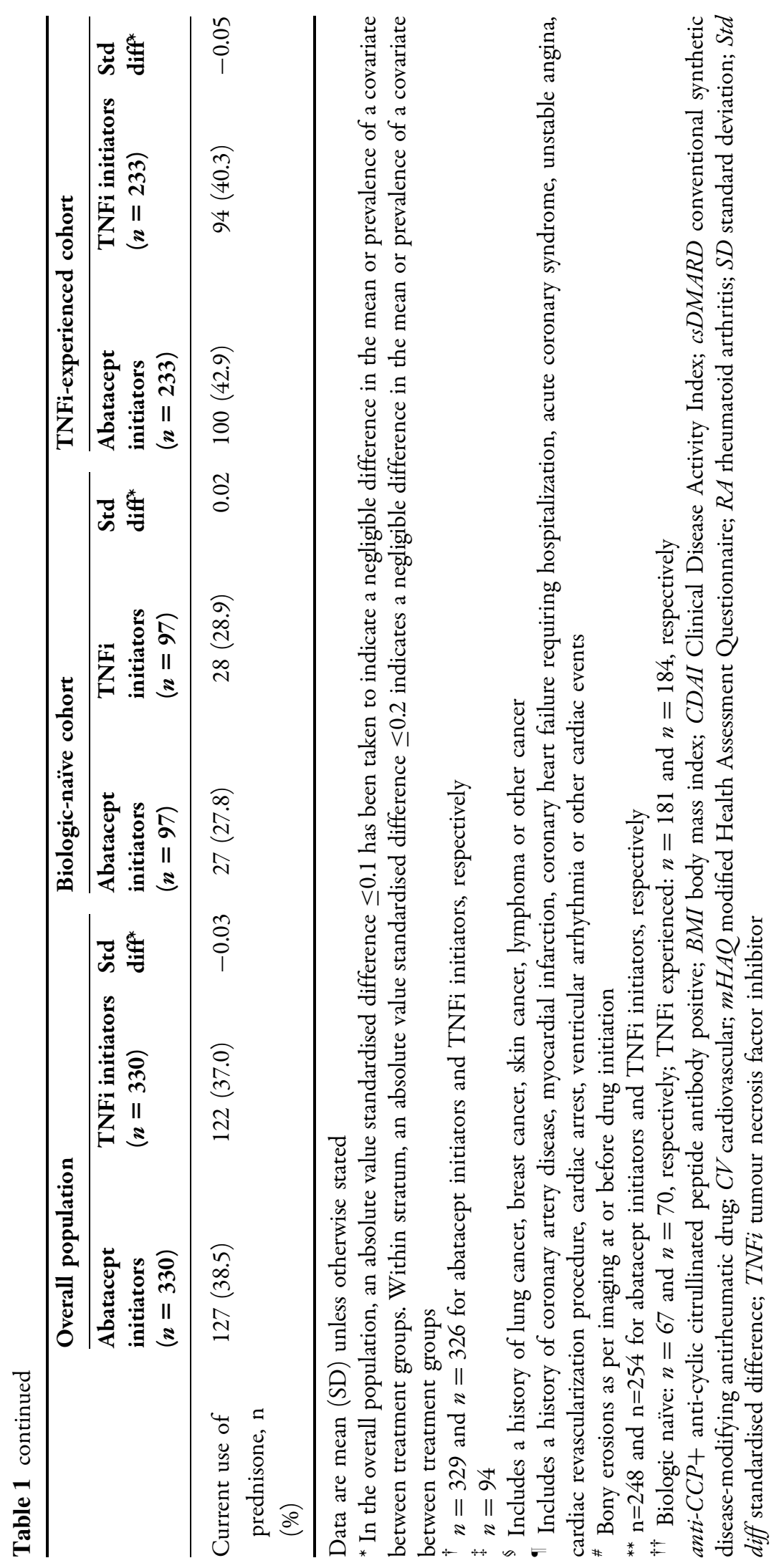




\begin{tabular}{|c|c|c|c|}
\hline & & & p value* \\
\hline \multicolumn{3}{|l|}{ Overall } & 0.24 \\
\hline \multirow{2}{*}{$\begin{array}{l}\text { Anti-CCP+ abatacept initiators }(n=330) \\
\text { Anti-CCP+ TNFi initiators }(n=330)\end{array}$} & 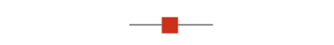 & $-9.85(-11.40,-8.30)$ & \\
\hline & 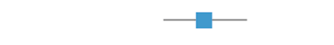 & $-8.53(-10.09,-6.98)$ & \\
\hline \multicolumn{2}{|l|}{ Biologic-naïve cohort } & & 0.19 \\
\hline Anti-CCP+ abatacept initiators $(n=97)$ & $\longrightarrow$ & $-9.81(-12.47,-7.15)$ & \\
\hline Anti-CCP+ TNFi initiators $(n=97)$ & $\square$ & $-12.31(-14.97,-9.66)$ & \\
\hline \multicolumn{2}{|l|}{ TNFi-experienced } & & 0.033 \\
\hline Anti-CCP + abatacept initiators $(n=233)$ & $\longrightarrow$ & $-9.87(-11.75,-7.98)$ & \\
\hline Anti-CCP + TNFi initiators $(n=233)$ & $\longrightarrow$ & $-6.96(-8.85,-5.08)$ & \\
\hline & $T$ & $\neg$ Abatacept & \\
\hline-20 & -15 & $0 \square \mathrm{TNFi}$ & \\
\hline \multicolumn{4}{|c|}{ Mean change in CDAl score $(95 \% \mathrm{Cl})$} \\
\hline
\end{tabular}

Fig. 2 Mean change from baseline in CDAI score over 6 months following initiation of treatment in propensity score-matched patients. The erosive disease variable was not included in the propensity score model as this variable was considered as a covariate of interest in Table 1 after the analysis was completed and, although the standardized difference for this variable was slightly higher than the 0.1

initiators, -9.81 [95\% CI -12.47 to -7.15$]$; TNFi initiators, -12.31 [95\% CI -14.97 to -9.66]; $p=0.19$ ). TNFi-experienced patients who were anti-CCP+ and who initiated abatacept had a significantly greater improvement in CDAI score than those initiating a TNFi (abatacept initiators, $-9.87[95 \% \mathrm{CI}-11.75$ to -7.98 ]; TNFi initiators, -6.96 [95\% CI -8.85 to -5.08$] ; p=0.033$ ).

\section{Secondary Efficacy Outcomes}

In both the overall population and the biologicnaïve and TNFi-experienced cohorts, mHAQ score improvement (Fig. 3) and binary outcomes (low disease activity, remission, mACR20 and mACR70; Fig. 4) at 6 months were similar between treatments. Among TNFi-experienced patients, abatacept initiators were more likely to achieve a mACR50 response than TNFi initiators [1.79 (95\% CI 1.12-2.86); $p=0.014]$.

Switching status was similar between the abatacept and TNFi initiators in the overall population and in the biologic-naïve cohort $(p=0.059$ and $p=0.87$, respectively; online supplementary table S3). However, TNFi-experienced abatacept initiators were more likely to threshold, the two cohorts were generally similar. *The $p$ value was reported from the test of the mean difference between the anti-CCP+ abatacept initiators and anti$\mathrm{CCP}+\mathrm{TNFi}$ initiators according to the primary outcome. Anti-CCP+ anti-cyclic citrullinated peptide antibody positive, $C D A I$ Clinical Disease Activity Index, $C I$ confidence interval, $T N F i$ tumor necrosis factor inhibitor

remain on treatment at 6 months than TNFi initiators (85.0 vs. $73.8 \% ; p=0.010)$.

\section{DISCUSSION}

Using data from Corrona, a large US-based RA registry, we compared the clinical effectiveness of abatacept versus TNFis among anti-CCP+ patients with moderate or high disease activity. To minimize selection bias, propensity scorematched cohorts of patients were stratified by prior TNFi use and compared. The results showed that patients with RA from real-world rheumatology practices who were anti-CCP+ and received either abatacept or a TNFi had a substantial improvement in clinical disease activity with no significant differences in outcomes between treatments in either the overall population or the biologic-naïve subgroup. TNFi-experienced, anti-CCP+ patients who initiated abatacept had a significantly greater change in CDAI score than those who initiated a TNFi. Switching status was similar between the abatacept and TNFi initiators in both the overall population and the biologic-naïve cohort; however, TNFi-experienced abatacept 


\begin{tabular}{|c|c|c|c|}
\hline & & & p value ${ }^{*}$ \\
\hline \multicolumn{3}{|l|}{ Overall } & 0.61 \\
\hline \multirow{2}{*}{$\begin{array}{l}\text { Anti-CCP + abatacept initiators }(n=330) \\
\text { Anti-CCP + TNFi initiators }(n=330)\end{array}$} & - & $-0.10(-0.14,-0.05)$ & \\
\hline & $\longrightarrow-$ & $-0.08(-0.13,0.04)$ & \\
\hline \multicolumn{2}{|l|}{ Biologic-naïve cohort } & & 0.42 \\
\hline \multirow{2}{*}{$\begin{array}{l}\text { Anti-CCP+ abatacept initiators }(n=97) \\
\text { Anti-CCP+ TNFi initiators }(n=97)\end{array}$} & $\longrightarrow$ & $-0.10(-0.20,-0.01)$ & \\
\hline & $\longrightarrow$ & $-0.16(-0.25,-0.06)$ & \\
\hline \multirow{3}{*}{$\begin{array}{l}\text { TNFi-experienced cohort } \\
\text { Anti-CCP+ abatacept initiators }(n=233) \\
\text { Anti-CCP + TNFi initiators }(n=233)\end{array}$} & & & 0.21 \\
\hline & $\longrightarrow$ & $-0.10(-0.15,-0.05)$ & \\
\hline & $\rightarrow-$ & $-0.05(-0.10,-0.0004)$ & \\
\hline \multirow{2}{*}{-0.4} & $T$ & $\neg \quad$ Abatacept & \\
\hline & -0.2 & $0.2=\mathrm{TNFi}$ & \\
\hline
\end{tabular}

Fig. 3 Mean change from baseline in mHAQ score over 6 months following initiation of treatment in propensity score-matched patients. ${ }^{*}$ The $p$ value was reported from the test of the mean difference between the anti-CCP+ abatacept initiators and anti-CCP+ TNFi initiators according to the primary outcome. Anti-CCP+ anti-cyclic citrullinated peptide antibody positive, $m H A Q$ modified Health Assessment Questionnaire, TNFi tumor necrosis factor inhibitor

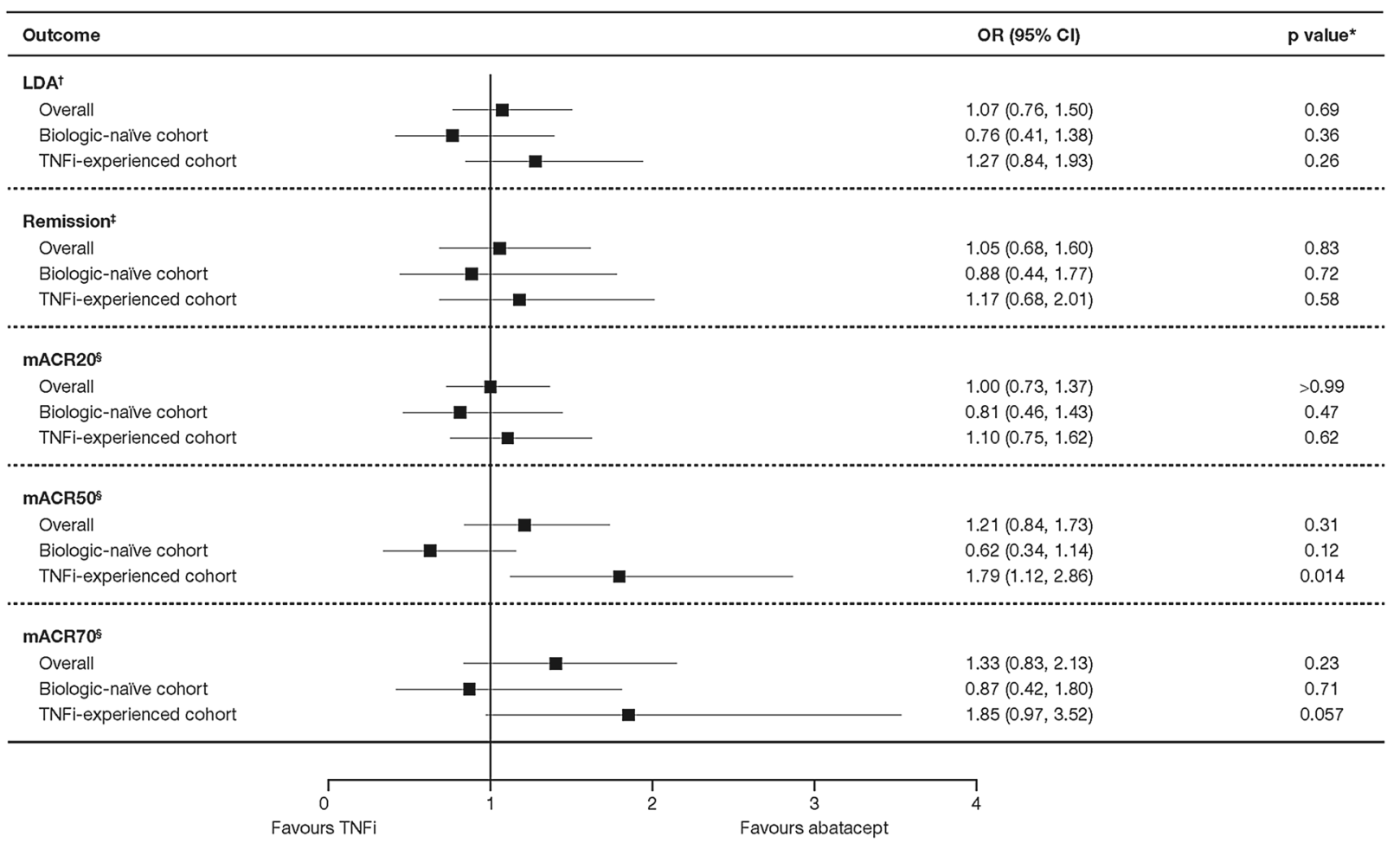

Fig. 4 Comparison of binary outcomes at 6 months between abatacept initiators and TNFi initiators in propensity score-matched patients. ${ }^{*}$ The $p$ value was reported for the difference in response rates between the anti-CCP+ abatacept initiators and anti-CCP+ TNFi initiators according to the primary outcome. ${ }^{\dagger} \mathrm{CDAI} \leq 10$ among those with moderate or high disease activity. ${ }^{\ddagger} \mathrm{CDAI} \leq 2.8$ among those with low disease activity or more severe disease activity. ${ }^{\S} \mathrm{mACR}$ is based on two out of four measures (it does not use erythrocyte sedimentation rate or C-reactive protein). Anti-CCP+ anti-cyclic citrullinated peptide antibody positive, $C D A I$ Clinical Disease Activity Index, $C I$ confidence interval, $m A C R 20 / 50 / 70$ modified American College of Rheumatology 20\%/50\%/ $70 \%$ response criteria, $O R$ odds ratio, $T N F i$ tumor necrosis factor inhibitor 
initiators were more likely to remain on treatment than TNFi initiators.

Data from clinical trials and real-world studies have consistently shown that abatacept response is related to antibody seropositivity in both MTX-naïve and MTX-experienced populations. Findings from the Abatacept versus Adalimumab Comparison in Biologic-Naïve RA Subjects with Background Methotrexate (AMPLE; NCT00929864) and Assessing Very Early Rheumatoid Arthritis Treatment (AVERT; NCT011472726) clinical trials have shown that abatacept in combination with MTX had a better clinical response in patients who exhibited a higher titers or seropositivity for multiple autoantibodies [14, 26, 27]. A post hoc analysis of AMPLE [14] also showed that, compared with baseline anti-CCP negativity, baseline anti-CCP positivity was associated with a better response for abatacept, an effect that was more pronounced in the higher anti-CCP+ quartiles [14]. In addition, a post hoc analysis of the Abatacept Trial to Gauge Remission and Joint Damage Progression in Methotrexate-Naïve Patients with Early Erosive RA (AGREE; NCT00122382) showed that abatacept in combination with MTX led to a decrease in autoantibody titers in patients with early RA who were positive for rheumatoid factor and/or ACPA antibodies and had evidence of erosion, resulting in some patients undergoing seroconversion to rheumatoid factor and ACPA seronegative status $[14,15]$. Conversion to ACPA seronegative status was associated with better clinical outcomes.

In addition to clinical trial data, real-world studies have similarly shown antibody seropositivity to be associated with abatacept response $[13,28]$. Data from the real-world Long-Term Experience with Abatacept in Routine Clinical Practice (ACTION; NCT02109666) study showed that, in biologic-naïve patients with RA, rheumatoid factor-positive and/or anti-CCP+ status was associated with greater efficacy and retention of intravenous abatacept than seronegative status [29]. Furthermore, a recent meta-analysis, including 19 studies, showed that the presence of anti-CCP positivity was associated with better EULAR responses in patients receiving abatacept treatment but not in patients treated with a TNFi [30]. Although the different efficacy endpoints in these trials may lead to differences in findings, taken together with the present analysis, these clinical trial data and real-world analyses support the use of abatacept in patients who are anti-CCP+, both for biologic-naïve patients and those who have previously failed TNFi therapy.

Experienced clinicians may not be surprised that there were no significant differences in the outcomes between treatments in biologic-naive patients. However, in patients who are anti$\mathrm{CCP}+$ who had already received one prior TNFi, our results suggest that abatacept was associated with better outcomes. These data provide value to physicians as they engage in conversations with anti-CCP+ patients regarding the pros and cons of second-line treatments and enable individualized treatment decisions.

Our study has several strengths. We utilized a large US-based registry of patients with RA with physician-validated outcome measures to examine the comparative effectiveness of initiating either abatacept or a TNFi in anti-CCP+ patients. The results from this real-world study in US patients support the clinical trial data $[14,26,27]$. Prior studies have suggested that patients in Corrona are representative of patients found in clinical practice in the US [31]. Finally, we were able to use advanced epidemiological methods (e.g., propensity score matching) to compare the responses to the different agents where selection bias may have existed.

This study also had some limitations. There is always concern that patients enrolled in registries may not reflect the type of patients observed elsewhere in general practice; however, this is a general limitation of all real-world observational studies. Also, as in any observational study, bias is a concern because physicians prescribe therapies based on the patient's profile, and treatment selection is not random. To overcome this limitation, the overall population and the two cohorts based on TNFi experience were analyzed, and propensity scores were matched between treatments, stratified by prior use of TNFi therapy. Finally, the Corrona RA Registry is a real-world patient population cared for by rheumatologists across 
the US; thus, there is no centralized laboratory evaluating serological status. This potential variability in serological testing was minimized in our study by categorizing patients according to anti-CCP status (i.e., positive vs. negative) rather than analyzing by anti-CCP titers. In addition, all patients derived from the CERTAIN substudy $(n=2795)$ had centralized measurement of CCP status.

\section{CONCLUSIONS}

In summary, the results of this US-based observational study indicate that patients with RA who were anti-CCP+ and received either abatacept or a TNFi had a substantial improvement in clinical disease activity after 6 months of treatment. In the overall propensity score-matched sample, similar outcomes were observed for both treatment groups. When considering the use of prior biologics, this propensity scorematched analysis demonstrated similar outcomes between the treatments in biologic-naïve patients; however, there was a greater reduction in disease activity among TNFi-experienced patients initiating abatacept versus those initiating a TNFi. The results from these analyses may be helpful to providers as they discuss treatment options for patients who are anti$\mathrm{CCP}+$. An increased awareness of individual patient characteristics, such as biomarkers, brings us closer to a personalized medicine approach.

\section{ACKNOWLEDGEMENTS}

The authors would like to thank all of the patients and providers who have participated in the Corrona RA registry.

Funding. This study was sponsored by Corrona, LLC and funded by Bristol-Myers Squibb. Bristol-Myers Squibb funded the article processing charges for this manuscript. Corrona has been supported through contracted subscriptions in the last 2 years by AbbVie, Amgen, Boehringer Ingelheim, Bristol-Myers Squibb,
Celgene, Crescendo, Eli Lilly and Company, Genentech, Gilead, GSK, Horizon Pharma USA, Janssen, Momenta Pharmaceuticals, Novartis, Pfizer Inc., Regeneron, Roche, Merck, UCB and Valeant. Drs Harrold and Litman had full access to all data in the study and take responsibility for the integrity of the data and the accuracy of the data analysis.

Medical Writing and Editorial Assistance. Professional medical writing and editorial assistance was provided by Claire Line, $\mathrm{PhD}$, at Caudex, and was funded by Bristol-Myers Squibb.

Authorship. All named authors meet the International Committee of Medical Journal Editors (ICMJE) criteria for authorship for this article, take responsibility for the integrity of the work as a whole, and have given their approval for this version to be published.

Authorship Contributions. All authors made a substantial contribution to the conception and design, execution, or analysis and interpretation of data for this study. All authors were involved in writing and critically drafting the article or revising it critically for important intellectual content. All authors approved the final version to be submitted for publication and agree to be accountable for all aspects of the work.

Disclosures. Leslie R. Harrold is an employee of Corrona, LLC, and the University of Massachusetts Medical School, has stock options in Corrona, LLC, has received grant funding from Pfizer, and is a consultant to Roche and Bristol Myers-Squibb. Heather J. Litman is an employee of Corrona, LLC. Sabrina Rebello is an employee of Corrona, LLC. Winnie Hua is an employee of Corrona, LLC. Sean E. Connolly has stock options/bond holdings in, and is an employee of Bristol-Myers Squibb. Evo Alemao has stock options/bond holdings in, and is an employee of Bristol-Myers Squibb. Sheila Kelly has stock options/bond holdings in, and is an employee of Bristol-Myers Squibb. Joel M. Kremer has stock options/bond holdings in, and is an employee of Corrona, LLC, and is a consultant 
for AbbVie, Amgen, BMS, Genentech, Lilly, Regeneron, Sanofi, and Pfizer. Joel M. Kremer has also received research grants from AbbVie, Genentech, Lilly, Novartis, and Pfizer.

Compliance with Ethics Guidelines. This study was carried out in accordance with the Declaration of Helsinki. All participating investigators were required to obtain full board approval for conducting noninterventional research involving human subjects with a limited dataset. Sponsor approval and continuing review was obtained through a central Institutional Review Board (IRB), the New England Independent Review Board (NEIRB, no. 120160610). For academic investigative sites that did not receive a waiver to use the central IRB, full board approval was obtained from the respective governing IRBs and documentation of approval was submitted to Corrona, LLC prior to initiating any study procedures. All registry patients were required to provide written informed consent and authorization prior to participating.

Data Availability. The datasets generated and/or analyzed during the current study are not publicly available, but are available from the corresponding author upon reasonable request. The Corrona dataset is based on a large US multicenter study adhering to a number of institutional review boards, with complex logistics. Patients did not provide consent to raw data sharing during the data collection for this purpose, and the Corrona data-sharing policies do not permit raw data sharing for this purpose. An aggregated limited dataset from the current analyses is available to qualified investigators with an approved protocol.

Open Access. This article is distributed under the terms of the Creative Commons Attribution-NonCommercial 4.0 International License (http://creativecommons.org/licenses/ by-nc/4.0/), which permits any noncommercial use, distribution, and reproduction in any medium, provided you give appropriate credit to the original author(s) and the source, provide a link to the Creative Commons license, and indicate if changes were made.

\section{REFERENCES}

1. Scott DL, Wolfe F, Huizinga TW. Rheumatoid arthritis. Lancet. 2010;376(9746):1094-108.

2. Kurowska W, Kuca-Warnawin EH, Radzikowska A, Maslinski W. The role of anti-citrullinated protein antibodies (ACPA) in the pathogenesis of rheumatoid arthritis. Cent Eur J Immunol. 2017;42(4):390-8.

3. Aletaha D, Neogi T, Silman AJ, Funovits J, Felson DT, Bingham CO 3rd, et al. 2010 Rheumatoid arthritis classification criteria: an American College of Rheumatology/European League Against Rheumatism collaborative initiative. Arthritis Rheum. 2010;62(9):2569-81.

4. van de Stadt LA, de Koning MH, van de Stadt RJ, Wolbink G, Dijkmans BA, Hamann D, et al. Development of the anti-citrullinated protein antibody repertoire prior to the onset of rheumatoid arthritis. Arthritis Rheum. 2011;63(11):3226-33.

5. Rantapaa-Dahlqvist $S$, de Jong BA, Berglin E, Hallmans G, Wadell G, Stenlund $H$, et al. Antibodies against cyclic citrullinated peptide and IgA rheumatoid factor predict the development of rheumatoid arthritis. Arthritis Rheum. 2003;48(10):2741-9.

6. Nielen MM, van Schaardenburg D, Reesink HW, van de Stadt RJ, van der Horst-Bruinsma I, de Koning $\mathrm{MH}$, et al. Specific autoantibodies precede the symptoms of rheumatoid arthritis: a study of serial measurements in blood donors. Arthritis Rheum. 2004;50(2):380-6.

7. Smolen JS, Landewé R, Bijlsma J, Burmester G, Chatzidionysiou $\mathrm{K}$, Dougados $\mathrm{M}$, et al. EULAR recommendations for the management of rheumatoid arthritis with synthetic and biological diseasemodifying antirheumatic drugs: 2016 update. Ann Rheum Dis. 2017;76(6):960-77.

8. van der Helm-van Mil AH, Verpoort KN, Breedveld FC, Toes RE, Huizinga TW. Antibodies to citrullinated proteins and differences in clinical progression of rheumatoid arthritis. Arthritis Res Ther. 2005;7(5):R949-58.

9. Hecht C, Englbrecht M, Rech J, Schmidt S, Araujo E, Engelke K, et al. Additive effect of anti-citrullinated protein antibodies and rheumatoid factor on bone erosions in patients with RA. Ann Rheum Dis. 2015;74(12):2151-6.

10. Katchamart W, Koolvisoot A, Aromdee E, Chiowchanwesawakit P, Muengchan C. Associations of rheumatoid factor and anti-citrullinated peptide antibody with disease progression and 
treatment outcomes in patients with rheumatoid arthritis. Rheumatol Int. 2015;35(10):1693-9.

11. Ajeganova S, Humphreys JH, Verheul MK, van Steenbergen HW, van Nies JA, Hafstrom I, et al. Anticitrullinated protein antibodies and rheumatoid factor are associated with increased mortality but with different causes of death in patients with rheumatoid arthritis: a longitudinal study in three European cohorts. Ann Rheum Dis. 2016;75(11): 1924-32.

12. Chatzidionysiou $\mathrm{K}$, Lie E, Nasonov E, Lukina G, Hetland ML, Tarp U, et al. Highest clinical effectiveness of rituximab in autoantibody-positive patients with rheumatoid arthritis and in those for whom no more than one previous TNF antagonist has failed: pooled data from 10 European registries. Ann Rheum Dis. 2011;70(9):1575-80.

13. Harrold LR, Litman HJ, Connolly SE, Kelly S, Hua $\mathrm{W}$, Alemao E, et al. Effect of anticitrullinated protein antibody status on response to abatacept or antitumor necrosis factor-alpha therapy in patients with rheumatoid arthritis: a US national observational study. J Rheumatol. 2018;45(1):32-9.

14. Sokolove J, Schiff M, Fleischmann R, Weinblatt ME, Connolly SE, Johnsen A, et al. Impact of baseline anti-cyclic citrullinated peptide 2 antibody titre on efficacy outcomes following treatment with subcutaneous abatacept or adalimumab: 2-year results from the AMPLE trial. Ann Rheum Dis. 2015;74(Suppl. 2):983-4.

15. Jansen DTSLEP, Smolen JS, Westhovens R, Le Bars M, Connolly SE, Ye J, Toes REM, Huizinga TWJ. Conversion to seronegative status after abatacept treatment in patients with early and poor prognostic rheumatoid arthritis is associated with better radiographic outcomes and sustained remission: post hoc analysis of the AGREE study. RMD Open. 2018;4(1):e000564 (in press).

16. Alessandri C, Bombardieri M, Papa N, Cinquini M, Magrini L, Tincani A, et al. Decrease of anti-cyclic citrullinated peptide antibodies and rheumatoid factor following anti-TNFalpha therapy (infliximab) in rheumatoid arthritis is associated with clinical improvement. Ann Rheum Dis. 2004;63(10): 1218-21.

17. Favalli EG, Raimondo MG, Becciolini A, Crotti C, Biggioggero $\mathrm{M}$, Caporali $\mathrm{R}$. The management of first-line biologic therapy failures in rheumatoid arthritis: current practice and future perspectives. Autoimmun Rev. 2017;16(12):1185-95.

18. Keystone EC, Kavanaugh AF, Sharp JT, Tannenbaum H, Hua Y, Teoh LS, et al. Radiographic, clinical, and functional outcomes of treatment with adalimumab (a human anti-tumor necrosis factor monoclonal antibody) in patients with active rheumatoid arthritis receiving concomitant methotrexate therapy: a randomized, placebo-controlled, 52-week trial. Arthritis Rheum. 2004;50(5): 1400-11.

19. Klareskog L, van der Heijde D, de Jager JP, Gough A, Kalden J, Malaise M, et al. Therapeutic effect of the combination of etanercept and methotrexate compared with each treatment alone in patients with rheumatoid arthritis: double-blind randomised controlled trial. Lancet. 2004;363(9410):675-81.

20. Lipsky PE, van der Heijde DM, St Clair EW, Furst DE, Breedveld FC, Kalden JR, et al. Infliximab and methotrexate in the treatment of rheumatoid arthritis. Anti-Tumor Necrosis Factor Trial in Rheumatoid Arthritis with Concomitant Therapy Study Group. N Engl J Med. 2000;343(22): 1594-602.

21. Maini R, St Clair EW, Breedveld F, Furst D, Kalden J, Weisman $\mathrm{M}$, et al. Infliximab (chimeric anti-tumour necrosis factor alpha monoclonal antibody) versus placebo in rheumatoid arthritis patients receiving concomitant methotrexate: a randomised phase III trial. ATTRACT Study Group. Lancet. 1999;354(9194):1932-9.

22. Singh JA, Saag KG, Bridges SLJ, Akl EA, Bannuru RR, Sullivan MC, et al. 2015 American College of Rheumatology guideline for the treatment of rheumatoid arthritis. Arthritis Care Res (Hoboken). 2016;68(1):1-25.

23. Martin-Mola E, Balsa A, Garcia-Vicuna R, GomezReino J, Gonzalez-Gay MA, Sanmarti R, et al. Anticitrullinated peptide antibodies and their value for predicting responses to biologic agents: a review. Rheumatol Int. 2016;36(8):1043-63.

24. Pappas DA, Kremer JM, Reed G, Greenberg JD, Curtis JR. Design characteristics of the CORRONA CERTAIN study: a comparative effectiveness study of biologic agents for rheumatoid arthritis patients. BMC Musculoskelet Disord. 2014;15(1):113.

25. Austin PC. An introduction to propensity score methods for reducing the effects of confounding in observational studies. Multivar Behav Res. 2011;46(3):399-424.

26. Huizinga TWJ, Connolly SE, Johnsen A, Zhu J, Furst DE, Bykerk VP, et al. Effect of anti-cyclic citrullinated peptide 2 immunoglobulin $M$ serostatus on efficacy outcomes following treatment with abatacept plus methotrexate in the AVERT trial. Ann Rheum Dis. 2015;74(Suppl 2):234-5.

27. Emery P, Burmester GR, Bykerk VP, Combe BG, Furst DE, Barre E, et al. Predictors of drug-free remission following treatment with abatacept (in 
combination with methotrexate or as monotherapy) in early rheumatoid arthritis. Arthritis Rheum. 2014;66(Suppl.):S1084.

28. Gottenberg JE, Courvoisier DS, Hernandez MV, Iannone $\mathrm{F}$, Lie $\mathrm{E}$, Canhao $\mathrm{H}$, et al. Brief report: association of rheumatoid factor and anti-citrullinated protein antibody positivity with better effectiveness of abatacept: results from the panEuropean registry analysis. Arthritis Rheumatol. 2016;68(6):1346-52.

29. Alten R, Nusslein HG, Mariette X, Galeazzi M, Lorenz HM, Cantagrel A, et al. Baseline autoantibodies preferentially impact abatacept efficacy in patients with rheumatoid arthritis who are biologic naive: 6-month results from a real-world, international, prospective study. RMD Open. 2017;3(1):e000345.

30. Alemao E, Postema R, Elbez Y, Mamane C, Finckh A. Presence of anti-cyclic citrullinated peptide antibodies is associated with better treatment response to abatacept but not to TNF inhibitors in patients with RA: a meta-analysis. Arthritis Rheumatol. 2017;69(suppl 10). Abstract 1034.

31. Greenberg JD, Kishimoto M, Strand V, Cohen SB, Olenginski TP, Harrington T, et al. Tumor necrosis factor antagonist responsiveness in a United States rheumatoid arthritis cohort. Am J Med. 2008;121(6):532-8. 